\title{
Em torno da literatura para todas as idades em José Eduardo Agualusa: algumas reflexões
}

\section{About Crossover Literature in José Eduardo Agualusa: Some Reflections}

Lola Geraldes XAvier [lolagrafias@gmail.com] 澳門理工學院 (Instituto Politécnico de Macau), China

Instituto Politécnico de Coimbra, Portugal

\section{RESUMO}

A literatura para a infância e juventude tem despertado atenções várias de académicos. O número de estudos nesse campo são bem o reflexo disso. Atualmente, porém, esta literatura já não pode ser vista como estanque. Há textos que, apesar de à primeira vista poderem ser percepcionados como tal, pela apresentação gráfica, sobretudo, ultrapassam essa etiqueta e inscrevem-se numa 'literatura para todas as idades'. São textos que cruzam as fronteiras entre públicos, escritos por autores que, geralmente, são especializados em literatura para adultos. Esta ficção crossover (Falconer, 2007 e Beckett, 2009), utilizando a denominação anglosaxónica, está também presente em alguns textos das literaturas africanas contemporâneas em português. Pretende-se, pois, aqui, mostrar alguns exemplos e particularidades dessa literatura africana para todas as idades. Nesse sentido, proceder-se-á a uma breve análise literária comparativa entre alguns textos literários de autores africanos e, em particular, do angolano José Eduardo Agualusa.

\section{Palavras-CHAVE}

Literaturas africanas em português; ficção crossover; José Eduardo Agualusa

\begin{abstract}
Children's and youth literature has attracted numerous attentions from academics. The number of studies in this field is a good reflection of this. Currently, children's literature can no longer be seen as a tight definition. There are some texts that, although at first sight can be perceived as such, by their illustration, they surpass this label and are inscribed in a literature for all ages. They are texts that intersect the boundaries between audiences, written by authors who are generally specialized in adult fiction. This crossover fiction (Falconer, 2007 e Beckett, 2009), using the Anglo-Saxon denomination, is a characteristic of some of the contemporary African literatures in Portuguese. Therefore, it is intended to show some examples and particularities of these African literatures for all ages. In this sense, a brief comparative literary analysis will be carried out between some African literary texts and in particular texts by the Angolan José Eduardo Agualusa.
\end{abstract}

\section{KEYWORDS}

African literatures from Portuguese speaking-countries; crossover fiction; José Eduardo Agualusa 
E se as histórias para crianças passassem a ser de leitura obrigatória para os adultos? Seriam eles capazes de aprender realmente o que há tanto tempo têm andado a ensinar?

(Saramago, 2014)

\section{Literatura para todas as idades}

A literatura infantil, herdeira da literatura oral, estimula a imaginação da criança e permite-lhe contactar com temas relacionados com a vida dos adultos, e, assim, construir a sua imagem sobre a realidade. De acordo com McDowell (1976), as características que permitem definir a literatura infantil são:

Children's books are generally shorter; they tend to favour an active rather than a passive treatment, with dialogue and incident rather than description and introspection; child protagonists are the rule; conventions are much used; the story develops within a clear-cut moral schematism which much adult fiction ignores; children's books tend to be optimistic rather than depressive; language is child oriented; plots are of a distinctive order, probability is often disregarded; and one could go on endlessly talking of magic, and fantasy, and simplicity and adventure. (apud Hunt e Ray 1996: 25)

No entanto, atualmente, assiste-se a textos categorizados como literatura para a infância que não preenchem totalmente estas características, interessando a um público mais abrangente e de faixas etárias diferentes.

Baseado na teoria dos atos de fala de Austin (1962) e de Searle (1969), Genette (1991) propõe a designação "ato de ficção" para explicar a instauração do universo fictício no espírito do leitor. Esta instauração acontece muitas vezes logo nas primeiras palavras do discurso ficcional, com expressões como "Era uma vez", produzindo um ato ilocutório diretivo, uma vez que faz um pedido de imaginação explícito.

Este "Era uma vez" inscreve a narrativa numa categoria específica, que tanto pode ser lida por um público infanto-juvenil, como adulto. Mudará, no entanto, a forma como este início é interpretado, a partir da enciclopédia literária e cultural do leitor. É um "Era uma vez" que pode também instaurar um universo inquietante de que a literatura não deve alhear-se:

Prefiro ler textos inquietos, que buscam caminhos novos, sobretudo na linguagem. Essa ambição, a meu ver, a boa literatura deve ter, menos para procurar edificar ou instruir o leitor, do que para inquietá-lo, causar-lhe surpresa e fazê-lo caminhar pelo inesperado (Almino 2012: 2).

O "Era uma vez" dos contos tradicionais populares está associado a narrativas infantis. Essas narrativas mostram intenções pedagógicas, de estímulo da imaginação, pretendendo proporcionar uma visão lúdica e pedagógica da realidade. Os temas e a linguagem são apresentados de modo a serem de fácil entendimento para as crianças.

Estas narrativas relativamente curtas, com presença de ilustrações, privilegiando o diálogo à descrição e em que as crianças (ou animais) são geralmente as personagens principais, podem, no entanto, interessar também a um público adulto. Veja-se o exemplo de Alice no país das maravilhas, de Lewis Carroll (1865). Como chama a atenção Beckett: "[...] many authors and critics have maintained that good children's literature must also appeal to adults" (Beckett 2009: 9). 
Efetivamente, há estórias como a Maior flor do mundo, de José Saramago, que nos remetem para um conceito aberto de literatura para todas as idades e que cruzam os limites entre públicos. Trata-se de uma ficção lida por adultos, jovens e crianças, que ultrapassa as fronteiras da idade e dos interesses do leitor. Esta literatura para todas as idades vem sendo apelidada de crossover fiction (Falconer 2007, 2009, 2010; e Beckett 2009, 2010), ou seja, “'crossover' in this context refers to literature written for children which crosses over to substantial numbers of adults readers" (Falconer 2007: 36).

Crossover fiction retoma a arte de contar estórias, uma antiga tradição da literatura, e como afirma Beckett (2009), a necessidade de estórias é atemporal, tanto para crianças como para adultos: "crossover literature addresses as diverse, cross generational audience that can include readers of all ages: children, adolescents, and adults" (Beckett 2009: 3-4).

Este fenómeno adequa-se aos tempos contemporâneos de identidades híbridas em sociedades líquidas (Bauman 2007, 2011) e permite a partilha de universos vivenciais entre as várias gerações. Esta literatura de fronteira serve de ponte entre a infância e a idade adulta, permitindo que pais e filhos partilhem um mesmo objeto artístico:

Crossover fiction recognizes the continuity that connects readers of all ages and acknowledges that different generations share experiences, knowledge, desires, and concerns. It offers a shared reading experience for all ages that brings the generation together in a better understanding of our world (Beckett 2010: 75).

Verificam-se, no entanto, diferenças entre as narrativas para a infância e juventude e as narrativas crossover. Estas últimas transcendem os horizontes de expectativas (Jauss, 1994) estritamente infanto-juvenis, apresentam uma ação não necessariamente linear, referências intertextuais e simbólicas, transcendendo o imaginário infantil. As alusões literárias são, pois, mais transversais. Os contágios e as intromissões de textos da não-ficção, a riqueza simbólica destas narrativas aliada a referências históricas, geográficas, artísticas, culturais, a intertextualidade e os recursos textuais remetem para a sofisticação dos textos e permitem vários níveis de leitura.

Por outro lado, as temáticas são também mais abrangentes e não exclusivamente para a infância e juventude:

Na narrativa crossover, temáticas de cariz existencial - vida, morte, identidade, perdas -, bem como a sugestão de universos fraturantes - divórcio, crise, drogas e toxidependência, negligências - são trazidas à tona, convidando o leitor não apenas a contemplá-las, mas a refletir e a compreendê-las como situações integrantes do seu contexto (Ramos e Navas 2015: 246).

As narrativas abertas e a explicitação de um narrador de primeira pessoa podem, igualmente, ser marcas da ficção crossover, bem como indícios, por vezes, de que se afastam do início das estórias infantis. Um exemplo é A maior flor do mundo que só começa algumas páginas depois de o narrador discorrer sobre a dificuldade de escrever estórias infantis e o princípio não é o convencional dos contos tradicionais: "Logo na primeira página, sai o menino pelos fundos do quintal, e, de árvore em árvore, como um pintassilgo [...]” (Saramago 2014: 7). Também não é comum, em estórias para crianças, o procedimento pós-moderno de intervenção do narrador 
na narrativa a que se assiste, igualmente, em A maior flor do mundo. A importância do narrador, qual contador de estórias, o uso recorrente de figuras de estilo, em particular da metáfora, e a sofisticada tessitura narrativa não deixam o leitor adulto alheio aos recursos estéticos da ficção crossover. Esta ficção "includes both conventional and avant-garde, sophisticated and straightforward, clear-cut and morally ambivalent novels" (Falconer 2009: 26).

A pergunta que se coloca é: por que é que os adultos começaram a ler esta literatura desde os anos noventa do século passado até aos nossos dias? Falconer (2009) baseia esses motivos em fatores sociais e, em particular, na mudança de gostos e hábitos dos leitores atuais, destacando que "our reading tastes are shifting to reflect changing views of childhood, adulthood and the ambiguous spaces in between" (Falconer 2009: 26). Também as crianças têm, hoje, mais contacto com temáticas e obras de adultos:

drug abuse, torture, depression, mental illness, death, the Holocaust and genocide are all subjects treated in contemporary children's literature, so whether or not they are consciously reading a novel 'for adults', today's children are arguably cross-reading more than they have in previous generations (Falconer 2009: 27).

Este diluir de fronteiras traduz uma maior hibridização da cultura entre adultos e crianças nos nossos dias, o que funciona nos dois sentidos. Não só os adultos leem narrativas que podem ter sido inicialmente pensadas para crianças e jovens, como estes leem narrativas tradicionalmente escritas para adultos.

Apesar de haver ainda poucos estudos sobre o assunto nas literaturas africanas de língua portuguesa, estas 'narrativas para todas as idades' estão aí igualmente presentes, inclusive, verificam-se alguns vasos comunicantes entre diferentes textos e autores. Veja-se o exemplo do angolano Ondjaki, em Ynari, a menina das cinco tranças (2002). Esta é uma estória de afetos, com uma mensagem simbólica de paz internacional em que as cinco tranças da protagonista representam os vários continentes num apelo à harmonia, solidariedade, fraternidade e paz entre os diferentes povos. Esta temática está também presente de modo metafórico e de forma interplanetária em Contos do país do arco-íris: Pan \& Geia (2015), do cabo-verdiano Mário Lúcio Sousa.

No final de Ynari, Ondjaki dirige-se aos "leitores de todas as idades":

Caros leitores de todas as idades,

para escrever uma estória como esta, eu tive que espremer um sonho [...]

Como eu não sei desenhar um pirilampo, vou deixar um espaço em branco para cada um imaginar o seu próprio pirilampo. Pode ser? (Ondjaki 2002: 43).

Este paratexto inscreve a obra na narrativa crossover e abre caminho a uma outra estória crossover sobre pirilampos: "Agora vou dizer uma coisa só porque me apetece mesmo: eu gosto muito de pirilampos... [...] então resolvi, agorinha mesmo, pôr aqui um pirilampo, espero que não se chateiem com o meu pirilampo de depois da estória" (Ondjaki 2002: 43) ${ }^{1}$.

1 Em 2000, José Eduardo Agualusa escrevera, já, um conto para explicar metaforicamente o aparecimento dos pirilampos "O primeiro pirilampo do mundo" na sua colectânea de contos para todas as idades: Estranhões \& Bizarrocos. 
Essa outra estória de Ondjaki será publicada mais tarde com o título: O convidador de pirilampos (2017), que por sua vez parece abrir um diálogo com O gato e o escuro de Mia Couto (2001), no que concerne ao 'medo' e ao 'escuro'. Vamos encontrar um diálogo entre o menino e o avô no texto de Ondjaki: “- Medo de quê? - Do escuro. [...] - O escuro é só um lugar sem luz. O mesmo lugar, com as mesmas coisas” (Ondjaki 2017: 13-14). Por sua vez, Mia Couto escreve o diálogo entre o escuro e a Dona Gata: “- Os meninos têm medo de mim [escuro]. Todos têm medo do escuro. - Os meninos não sabem que o escuro só existe é dentro e nós” (Couto 2001: 16).

Os livros de Mia Couto sugeridos pelo Plano Nacional de Leitura (PNL) português como literatura para a infância e juventude inscrevem-se também, em nosso entender, na ficção para todas as idades, pela complexidade metafórica e ambivalência de leituras que permitem ao leitor, segundo a idade e o universo de saberes. É o caso de O gato e o escuro (2001), A chuva pasmada (2004) e O beijo da palavrinha ${ }^{2}$ (2006). Das personagens animais ou inanimadas de O gato e o escuro, passa-se para as personagens humanas de A chuva pasmada e de O beijo da palavrinha. Personagens pobres, algumas acusadas de serem desprovidas de juízo, como o irmão de Maria Poeirinha, de O beijo da palavrinha, ou o narrador de A chuva pasmada: "meus pais sempre me tinham chamado de pasmado. Diziam que eu era lento no fazer, demorado no pensar. Eu não tinha vocação para fazer coisa alguma. Talvez não tivesse mesmo vocação para ser" (Couto 2004: 9).

Sobre A chuva pasmada refere Mia Couto numa entrevista: "Acabei agora uma coisa chamada 'A Chuva Pasmada'. É um livro que começou por ser um livro infantil, mas não gosto dessa maneira de o chamar, e evoluiu para uma outra coisa. Já não é um livro para crianças, é um livro. Só que tem ilustrações" (Beal 2005: s. p. - sublinhado nosso).

De facto, o uso das ilustrações só por si já não permite, atualmente, a categorização de textos infantis. Estas narrativas comungam cada vez mais de temáticas com os textos normalmente dirigidos a leitores adultos, como é o caso do uso de mitos, de tradições africanas, de temas como a morte, o medo, a poluição e agressão ao meio ambiente pelo Homem, associados a jogos de palavras, o que aumenta a complexidade linguística e estética destes textos, como se constata em Mia Couto.

\section{Narrativas para todas as idades: José Eduardo Agualusa}

José Eduardo Agualusa, escritor angolano, tem escrito também para crianças e jovens. Trata-se do escritor africano de língua portuguesa mais sugerido pelo Plano Nacional de Leitura, em Portugal $^{3}$. Autor de uma vasta obra literária (poesia, crónicas, romances, contos), o escritor usa os preceitos do Pós-modernismo (Hutcheon, 1991), como o hibridismo, para, a partir do espaço histórico de Angola ou de outros espaços da lusofonia, visar o universal. É esse universal que está patente

2 O beijo da palavrinha e O gato e o escuro são recomendados pelo PNL (Plano Nacional de Leitura português) dos 9-11 anos: http://catalogolx.cm-lisboa.pt/ipac20/ipac.jsp?session=\&profile=pnl2027\&source= !rbml\&view=subscriptionsummary\&uri=full=3100024 !465877 !2\&ri=4\&aspect=subtab11\&res=298\&menu=search\&ipp=1\&spp=1\&staffon$\mathrm{ly}=\&$ term $=$ Mia\%20 couto\&index $=. \mathrm{GW} \& u i n d e x=\& \mathrm{menu}=$ search\&ri=4.

3 É, também, um autor bastante premiado, destacando-se, em 2017, o Prémio Literário Internacional de Dublin pelo seu romance Teoria geral do esquecimento (2012) - A general theory of oblivion, na tradução de Daniel Hahn. Agualusa tornou-se, assim, no primeiro autor de língua portuguesa a vencer um dos mais prestigiados prémios literários mundiais, atribuído à edição em inglês. 
nos seus textos para todas as idades, nomeadamente em Estranhões \& Bizarrocos (primeira edição de 2000), A girafa que comia estrelas (primeira edição de 2005) e A rainha dos estapafúrdios (primeira edição de 2012) $)^{4}$. Estes livros não são primariamente dirigidos a adultos, estando inscritos nas sugestões do Plano Nacional de Leitura ${ }^{5}$ em Portugal para as crianças.

Tendo publicado até ao momento quase uma dezena de livros de contos, as suas narrativas breves abordam questões de natureza histórica, social e política, trabalhados ficcionalmente. As personagens ora representam figuras históricas, ora se baseiam em pessoas comuns. Normalmente estão presentes elementos da História e cultura angolanas e de outros países de língua portuguesa (sobretudo Brasil e Portugal). O empenhamento político é visível em alguns contos (e romances) como é o exemplo em O livro dos camaleões de "O bom déspota" (Agualusa 2015). Trata-se de uma referência ao ex-presidente de Angola, José Eduardo dos Santos, num texto todo ele construído em torno da ironia. Neste livro de contos não infantil, por exemplo, "A sombra da mangueira" bem poderia ser um conto para todas as idades. Trata-se de uma narrativa em que a criatividade e o fantástico se destacam. Ao lembrar intertextualmente Le Petit Prince de Antoine de Saint-Exupéry, a construção dialógica, os constantes aforismos, o carácter pedagógico e inventivo do conto fazem este texto partilhar de características da crossover fiction. Falconer destaca a forma como estes textos funcionam narrativamente e se entrecruzam:

Although crossover fiction is interesting for cultural reasons, the fact that children's fiction is crossing to adult readerships should also afford us the opportunity to appreciate these works for their formal attributes: their characterisation, emplotment, style, structure and all the other distinctive aspects of the ways these texts work as fictional narratives (Falconer 2009: 31).

Outro aspeto que sobressai neste conto é o caráter metaliterário, no sentido em que o texto, ele próprio, reflete sobre a escrita literária: "A escrita ajudava-me a ver. [...] Só vale a pena escrever sobre aquilo que desconhecemos. O que nos inquieta. O que nos aterroriza" (Agualusa 2015: 20).

Este cruzamento entre fronteiras etárias é muito visível em Estranhões \& Bizarrocos. A primeira frase da primeira narrativa deste livro, que apresenta a personagem do conto "Estranhões, Bizarrocos e outros seres sem exemplo", poderia sintetizar metaforicamente as estórias desta coletânea: "Jácome era um inventor de coisas impossíveis [...]. Não se podia dizer dele que não tinha imaginação - tinha e de sobra" (Agualusa 2013: 8). De facto, estas narrativas falam-nos de "coisas impossíveis", alargando o horizonte de expetativas e exigindo vasta imaginação ao leitor.

Trata-se de uma coletânea composta por dez contos (que formam um verdadeiro macrotexto) e "que sugerem, logo num primeiro contacto verbal e visual, um percurso interpretativo baseado na ideia de aventura ou de privilégio da 'inventividade" (Vieira 2001: 22). Esta "inventividade" é acentuada ab initio pelo paratexto do subtítulo: [estórias para adormecer anjos]. Estes anjos não são apenas as crianças, são os leitores que mostrarem capacidade para sonhar. Este subtítulo é convocado também no conto "O sonhador". Aí, o pequeno Carlos sonha com o nascimento de anjos. Estes nascem após o pôr-do-sol, a partir de abóboras douradas na areia de uma praia. José

4 Livros recomendados pelo PNL dos 6 aos 8 anos (Estranhões \& Bizarrocos e A girafa que comia estrelas) e dos 9 aos 11 anos (A rainha dos estapafúrdios).

5 http://www.pnl2027.gov.pt/np4/livrospnl?cat_livrospnl=catalogo_blx 
Eduardo Agualusa utilizará aforismos para mote de alguns dos seus contos, neste caso: "o poente [é a ] hora dos anjos".

As construções de sentidos, por inferência, "induzem, à partida, à aceitação tácita de uma leitura deste texto literário, com base nos protocolos da designada literatura maravilhosa" (Silva 2007: 777). De facto, se entendermos maravilhoso como um "mundo contrafactual, onde estão derrogadas todas as leis, regras e convenções do mundo empírico" (Silva 1981: 13), estes contos de Agualusa denotam vários elementos do maravilhoso. Mas este maravilhoso é reinventado de modo a ser experienciado por um leitor de qualquer idade. É um maravilhoso que se compõe de mundos metafóricos e se alimenta do caráter subversivo, ou do nonsense, do comportamento de algumas personagens e do insólito de situações. Os dez contos são caracterizados por uma textualização criativa ou lúdica, em que a transgressão de um mundo empírico e histórico-factual permite enfatizar valores intemporais. Trata-se de contos que exigem do leitor capacidade de observação e análise bem como capacidade de entrar num mundo 'alternativo' em que os animais, enquanto personagens, apresentam características humanas. Destes contos, metade tem como personagens principais animais. São textos que questionam a relação ordem-caos, realidade-criatividade ilimitada.

O narrador, normalmente, mostra-se presente em vários contos, quer como responsável inequívoco da narração, em "O país dos contrários": "Quero que conheçam este gato. [...] Falo-vos de um gato, digamos assim, muito ambicioso.” (Agualusa 2013: 38); quer como aquele que apoia a leitura do texto, explicando, em "Sábios como camelos": "À frente da cáfila, que é como se chama uma fila de camelos [...]” (Agualusa 2013: 14). É um narrador que, qual contador de estórias, não se esquece que tem público e se dirige a ele, fazendo esclarecimentos e dando opinião: "Isto foi há muito tempo. Mas há quem diga que, quando estão sozinhos, os camelos ainda conversam entre si. Pode ser" (Agualusa 2013: 18). Estas intromissões, ao estilo pós-moderno ${ }^{6}$, evidenciam um narrador que manipula a estória e a comenta, como se pode ler no final do conto sobre a reprodução dos cavalos-marinhos, "O pai que se tornou mãe":

Talvez há pouco eu me tenha enganado. Parece-me agora que esta história tem um final feliz. Porque decidi que ela acaba aqui, num nascimento, e porque a partir daquela manhã de sol, passou a existir neste nosso planeta um pai que dá à luz (Agualusa 2013: 52).

No que diz respeito a "Sábios como camelos", trata-se de um conto todo ele alegórico em relação ao conhecimento construído em torno do aforismo que dá título ao texto. O leitor poderá também aqui estabelecer uma relação intertextual com $O$ incrível rapaz que comia livros (primeira edição de 2007), de Oliver Jeffers.

Aquilo que pode ser uma leitura linear, ainda que criativa, de uma criança, de "O país dos contrários", convocará conhecimentos do leitor adulto, por exemplo, através do nome da personagem, o gato Felini, numa aparente invocação do cineasta italiano Federico Fellini. O conto é sobre um gato, Felini, que se apaixona por Graciosa, uma vaca. Ao longo da estória assiste-se ao desenrolar de peripécias insólitas em que os animais apresentam atitudes humanas. O texto é uma provocação, de imaginação contra a normalidade, sobre o mundo da fantasia, difícil de aceder aos adultos,

6 Para uma síntese das características pós-modernas nas literaturas africanas ver, por exemplo, Xavier (2007, 2019). 
e aflora questões da mestiçagem e ambiguidade identitária. Trata-se de uma narrativa fechada, mas com um desfecho irónico, que permite inscrever o conto no ludismo imaginativo e linguístico para que muito contribui a expressividade das antíteses e hipérboles.

Também em A girafa que comia estrelas se assiste à reinvenção da realidade. Trata-se de um texto lúdico que convoca no leitor a imaginação criativa e sinestésica. O texto aborda a amizade improvável entre as personagens principais: uma girafa e uma galinha-do-mato. Desta narrativa, destaca-se a criatividade, o nível pedagógico, a transcrição de provérbios e o questionamento sobre a realidade humana: "Os homens são animais estranhos: vivem empoleirados uns em cima dos outros, em grandes galinheiros. Estão sempre com pressa, correm o tempo todo, como formigas, de um lado para o outro, e acham que são felizes assim" (Agualusa 2012: 14). A leitura do mesmo texto por leitores de idades diferentes terá necessariamente consequências na interpretação. Nesta passagem, por exemplo, um leitor adulto poderá encontrar relações intertextuais com O Papalagui - Discursos do chefe da tribo de Tiavéa nos mares do sul, do chefe Tuiavii.

O humor e a ironia são características presentes em narrativas de José Eduardo Agualusa. O humor, em particular, é a característica que potencia $A$ rainha dos estapafúrdios como uma narrativa para todas as idades. A rainha dos estapafúrdios comunga, com os contos referidos anteriormente, a dimensão lúdica e humorística que, pelo discurso estético expressivo, criativo e inovador, é transversal a todas as idades. A mensagem do conto é também pedagógica, enfatizando-se o poder da inteligência em detrimento do tamanho. A personagem principal é uma perdigota, que, num primeiro momento sofre as consequências da sua audácia e vaidade. No entanto, em vez de ficar a lamentar-se da sua nova malfadada situação, usa toda a sua coragem, perspicácia e ousadia para reverter a posição. Consegue, assim, ser admirada e respeitada por todos os animais selvagens (menos o leão):

- Vais comer-me?

- Não sei - confessou a hiena. - Primeiro tenho de saber que coisa és tu. Não como objetos não identificados. (...)

- Sou Dona Ana I, a Rainha dos estapafúrdios!

- [...] E o que fazes tão longe de casa?

- Caço. Ando à caça de leões.

- Leões?! [...] Tu, com essa magra figura, Dona Ana I, tu caças leões? (Agualusa 2012: 13-14).

O cómico de situação, provocado pelo contraste da desproporção entre o tamanho e a coragem da perdigota face à hiena e ao leão (noutro momento da narrativa) criam momentos lúdicos transversais a todas as idades.

A realidade constrói-se, pois, através da palavra, do discurso. Os títulos destes livros para todas as idades de José Eduardo Agualusa abrem $a b$ initio um universo de fantasia e criatividade que condiciona desde o começo a leitura criadora dos textos. 


\section{Em conclusão}

A literatura é exercício de alteridade, que inquieta o leitor e o desafia a sacudir o preconceito. Nesse sentido, como sintetiza a escritora portuguesa Ana Margarida de Carvalho, "o escritor é aquele que consegue ainda ter um olhar quase infantil sobre as coisas, conseguir deslumbrar-se com um bichinho no corredor do parlatório, nunca perder esse olhar de primeira vez" (Gonçalves 2018). Este olhar "quase infantil" permite não só o acesso à criatividade e imaginação, como aproxima mais facilmente o escritor de todas as camadas etárias, podendo facilitar a escrita para todas as idades.

Esta literatura para todas as idades é uma literatura que apela à criatividade ficcional e linguística e que vai ao encontro das características da boa literatura que João Almino defende:

A ficção, para fazer jus a seu próprio conceito, deve ser criativa - livre e fundadora, capaz de libertar a própria liberdade de seus sentidos já adquiridos. A boa literatura é aquela, então, que está disposta a liberar a imaginação, a surpreender, a fazer avançar o pensamento, a romper com as formas estabelecidas pela política e pelo próprio saber. Por isso, pode ao mesmo tempo dar prazer e incomodar (Almino 2012: 2).

A literatura para todas as idades apresenta reminiscências dos contadores de estórias, os "pirivelhos", aqueles que "não devem ser encontrados", como escreve Ondjaki (2017: 2), em O convidador de pirilampos. É uma literatura que atravessa fronteiras etárias e de interesses: "as narrativas crossover ultrapassam o endereçamento da obra a um público específico e comprovando a pluralidade de experiências de leituras possíveis que delas decorrem" (Ramos e Navas 2015: 255).

A sua criatividade narrativa e linguística inscreve-a num cânone literário alargado. O narrador, normalmente omnisciente, assemelha-se a um contador de estórias, que atravessa os tempos e a história, de um "antigamente" aos dias de hoje, intromete-se na narrativa e aproxima-a do leitor.

O intuito pedagógico, expresso na escolha das personagens e tramas narrativas, mas também os aforismos e outras tradições populares, como provérbios e moral que muitos textos apresentam, acercam estes textos da literatura para a infância e juventude. A literatura para a infância e juventude encoraja a faculdade de imaginação, é: "intellectually stimulating, encouragingly readable, linguistically challenging, literarily fulfilling, and educationally rewarding" (Ho 2000: 269). No entanto, estes textos para todas as idades não preenchem apenas estes requisitos. Trata-se de textos que oferecem uma amplitude temática considerável: da vida real a temas imaginativos, de história e cultura a mitologia, lendas, ficção científica, fantasia, sobrenatural, realismo mágico, maravilhoso. Assim, os conhecimentos enciclopédicos que exigem do leitor, a profundidade da reflexão que impõem, a criatividade e originalidade que apresentam cativam também o público adulto.

Estas são apenas algumas considerações sobre crossover fiction, através de uma leitura de textos que tentam ir no sentido de Falconer (2009: 57): "but whether one is 'for' or 'against' it, it is worth stressing that 'crossover fiction' can really only be defined by what it does, rather than what it is."

Será necessário desenvolver os estudos neste âmbito dos textos para todas as idades nas literaturas africanas em língua portuguesa. Aqui, simplesmente, pretendeu-se iniciar reflexões em torno, sobretudo, de algumas narrativas de José Eduardo Agualusa. 


\section{Referências bibliográficas}

Agualusa, J. E. (2015). O livro dos camaleões. Lisboa: Quetzal.

- (2013). Estranhões \& Bizarrocos [estórias para adormecer anjos]. Lisboa: D. Quixote.

. (2012). A rainha dos espatafúrdios. Lisboa: D. Quixote.

. (2012). A girafa que comia estrelas. Lisboa: D. Quixote.

Almino, J. (2012). Como escrevo a ficção. Luso-Brazilian Review, 49, 2, 1-4.

Austin, J. L. (1962). How to do things with words. Oxford: Oxford University Press.

Bauman, Z. (2007). Liquid times. Living in an age of uncertainty. Cambridge/Malden: Polity Press.

. (2011). Culture in a liquid modern world. Cambridge/Malden: Polity Press.

Beal, S. (2005). Entrevista com Mia Couto: jogo das reinvenções. <https://www.lainsignia.org/2005/marzo/ cul_030.htm>.

Beckett, S. (2009). Crossover fiction: global and historical perspectives. New York: Routledge.

- (2010). Crossover fiction: creating readers with stories that address the big questions. In A. Nóvoa

(Ed.), Formar leitores para ler o mundo (pp. 65-76). Lisboa: Fundação Calouste Gulbenkian.

Couto, M. (2013). O beijo da palavrinha. Lisboa: Caminho.

- (2004). A chuva pasmada. Lisboa: Caminho.

. (2001). O gato e o escuro. Lisboa: Caminho.

Falconer, R. (2007). Crossover literature and abjection: Geraldine McCaughrean's The white darkness. Children's literature in education, 38, 1, 35-44.

- (2009). The crossover novel: contemporary children's fiction and its readership. New York: Routledge.

. (2010). Young adult fiction and the crossover phenomenon. In D. Rudd (Ed.), The Routledge Companion to children's literature (pp. 87-99). New York: Routledge.

Genette, G. (1991). Fiction et diction. Paris: Éditions du Seuil.

Gonçalves, S. (2018). A literatura não serve para te sossegar ou tranquilizar com o mundo - Entrevista a Ana Margarida de Carvalho". Ponto final, 18-3-2018. <https://pontofinalmacau.wordpress.com/2018/03/18/a-

-literatura-nao-serve-para-te-sossegar-ou-tranquilizar-com-o-mundo/>

Ho, L. (2000). Children's literature in adult education. Children's literature in education, 31, 4, 259-271.

Hutcheon, L. (1991). Poética do pós-modernismo: história, teoria, ficção. Rio de Janeiro: Imago.

Hunt, P.; \& Ray S. (Eds.). (1996). International companion encyclopaedia of children's literature. London: Routledge.

Jauss, H. R. (1994). A história da literatura como provocação à teoria literária. São Paulo: Ática.

Jeffers, O. (2018). O incrível rapaz que comia livros. Lisboa: Ouro Negro.

Ondjaki. (2017). O convidador de pirilampos. Lisboa: Caminho.

. (2002). Ynari, a menina das cinco tranças. Luanda: Chá de Caxinde.

Ramos, A. M.; \& Navas, D. (2015). Narrativas juvenis: o fenómeno crossover nas literaturas portuguesa e brasileira. Elos. Revista de literatura infantil exuvenil, 2, 233-256.

Saramago, J. (2014). A maior flor do mundo. Porto: Porto Editora.

Searle, J. (1969). Speech Acts. Cambridge: Cambridge University Press.

Silva, S. R. da (2007). Estranhões \& Bizarrocos (estórias para adormecer anjos), de José Eduardo Agualusa e a aventura da "inventividade". In P. Laranjeira, M. J. Simões, \& L. Geraldes Xavier (Eds.), Cinco Povos Cinco Nações (pp. 776-784). Lisboa: Novo Imbondeiro. 
Silva, V. A. e (1981). Nótula sobre o conceito de literatura infantil. In D. Guimarães de Sá (Ed.), A literatura infantil em Portugal (pp. 11-15). Braga: Editorial Franciscana.

Sousa, M. L. (2015). Contos do país do arco-íris - Pan \& Geia. Macau: IPOR/ADCC.

Tiavea, T. de (2010). O Papalagui - discursos de Tuiavii chefe de tribo de Tiavéa nos mares do sul. Lisboa: Antígona.

Vieira, V. A. (2001). Estranhões \& Bizarrocos. Malasartes - cadernos de literatura para a infância e a juventude, 5, 22.

Xavier, L. G. (2007). O discurso da ironia. Lisboa: Novo Imbondeiro.

. (2019). Literaturas africanas em português: uma introdução. Macau: Instituto Politécnico de Macau. 
